\title{
Mechanical Braking System for the Pulsed Power Supply System of ASDEX Upgrade
}

\author{
C.-P. Käsemann $^{\mathrm{a},{ }^{*}}$, M. Huart ${ }^{\mathrm{a}, \mathrm{d}}$, F. Stobbe ${ }^{\mathrm{a}}$, I. Goldstein ${ }^{\mathrm{a}}$, A. Sigalov ${ }^{\mathrm{a}}$, E. Sachs ${ }^{\mathrm{b}}$, E. Perk $^{\mathrm{c}}$ \\ and the ASDEX Upgrade Team
}

\author{
${ }^{a}$ Max Planck Institute for Plasma Physics, EURATOM Association, Boltzmannstr. 2, 85748 Garching, Germany \\ ${ }^{b}$ Siemens AG, Industrial Automation Systems, Gleiwitzer Straße 555, 90475 Nürnberg, Germany \\ ${ }^{c}$ Piper Test \& Measurement Ltd., The Barn, Bilsington, Ashford, Kent TN25 7JT, England, United Kingdom \\ ${ }^{d}$ Michel Huart Personal Coaching \& Consulting, Georgenschwaigstraße 23 RG, 80807 München, Germany
}

A few years ago, IPP reviewed the safety of the ASDEX Upgrade pulsed power supply system. Two critical sub-systems had been identified: The (electrical) braking system for the flywheel generators and the oil lubrication system for the shaft bearings. A simultaneous failure of these two systems may lead to severe damages and could have consequences for the safety of operating personnel. Therefore a second, independent braking possibility for every generator was stipulated. Especially the challenges adapting a dynamometer, originally designed for motor test benches, towards a plant safety system for generator EZ4 will be described in the paper. Further on, the paper will present the problems, implementing such a system into an existing installation, including the calculation of the required supporting structure, balancing of the extended shaft line and required water cooling and control. Finally it will report on the performance achieved during operation.

Highlights - Compact and innovative solution for dumping of large kinetic energy.

- Small mass of energy converter at the shaft due to circulating storage medium.

- Design of the active parts ensures flat torque/power characteristics.

- Also suitable for spending a great part of operating life in "Freewheeling" mode.

Keywords: ASDEX Upgrade; Flywheel generator; Power supply; Hydraulic dynamometer

\section{Introduction}

The pulsed power supply system of ASDEX Upgrade is based on three large flywheel generators (EZ2, EZ3 and EZ4) with a total rated deliverable energy of $2768 \mathrm{MJ}$ (1650-1275 rpm) (Fig. 1). The stored energy at maximum speed (1650 rpm) is 2.48 times this value, or $6860 \mathrm{MJ}$, which must be dissipated in case of emergency. Further in case of loss of auxiliary power, this stored energy must be dissipated within the run-off time of the gravity-fed oil lubrication systems of the generators $(\sim 10 \mathrm{~min})$. To satisfy these demands, powerful and reliable braking systems are required.

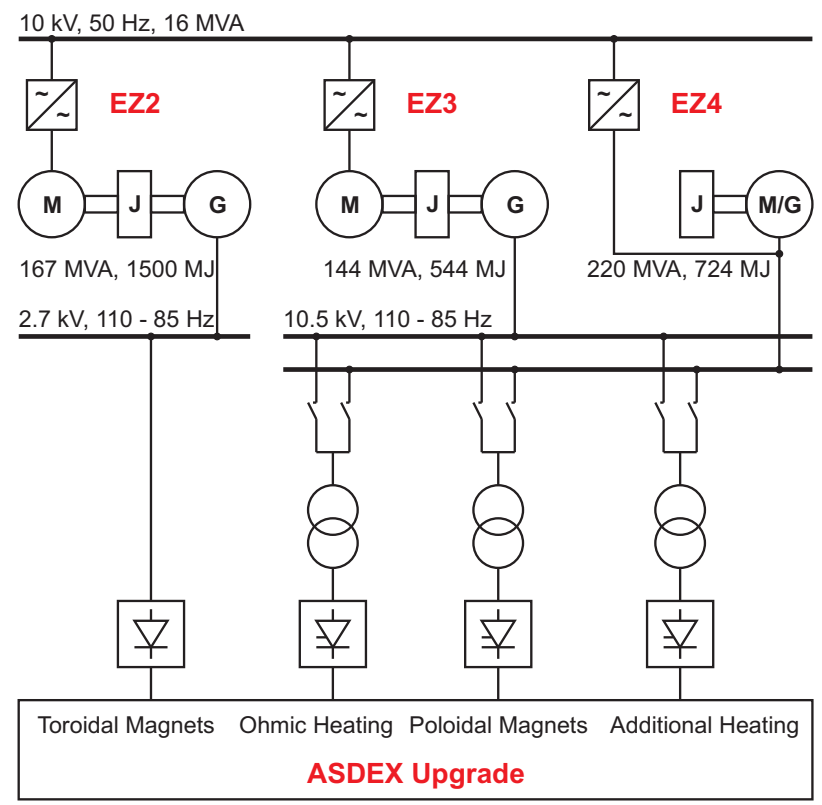

Fig. 1 AUG Pulsed Power Supply Network
Reliability is met by having a second, independent braking possibility for every generator. At the generators EZ2 and EZ3, a new electrical braking at the generator side supplements the electrical braking of the motor drive (Fig. 2). Generator EZ4 is a combined motor/generator. Therefore an additional electrical braking is not possible. Furthermore, the space available for an extension of the shaft line in the existing building is very limited $(\sim 3 \mathrm{~m})$.

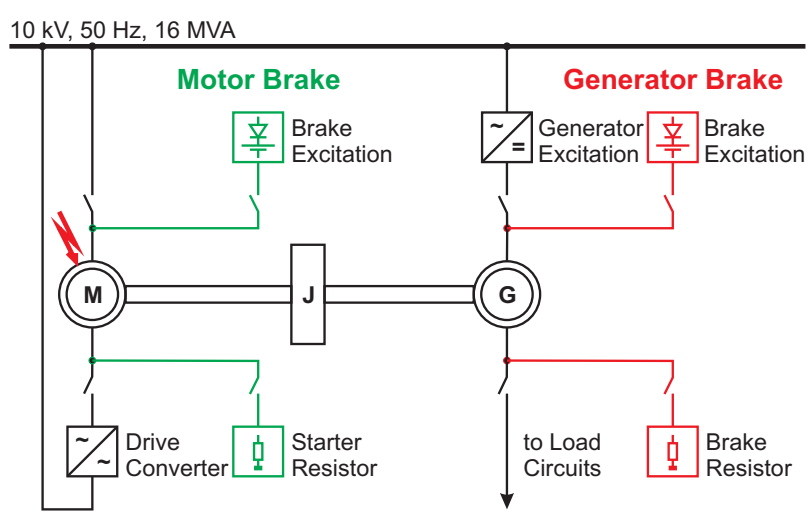

Fig. 2 Electrical Generator Braking System at EZ2 and EZ3

\section{Application}

To meet the demand on available space, a solution, in which the energy converter (kinetic $\rightarrow$ thermal) is separate from the thermal energy storage, was opted for. The hydraulic dynamometer, normally used for large engine test-beds, in which the kinetic energy is dissipated directly in the circulating water, meets this condition. However, the narrow speed range of an engine test-bed differs from that of a generator braking system. The torque versus speed curve depends on the design of 
the rotor/stator discs of the dynamometer. In the dynamometer selected, type PH9000, the special design of the rotor/stator discs ensures a very flat torque/power in an extended speed range (constant torque of $50 \mathrm{kNm}$ between 500 and $1300 \mathrm{rpm}$, constant power of $6.7 \mathrm{MW}$ between 1300 and $2500 \mathrm{rpm}$ ).

At low speed, the braking is assisted by a mechanical disc brake $(20 \mathrm{kNm})$, engaged by a clutch at $200 \mathrm{rpm}$. To ensure a smooth integration of the project and to reduce costs, the project management, the design study of the water tank to store and dissipate the $1800 \mathrm{MJ}$ of stored energy as well as the control of the water system were undertaken by IPP staff.

The Mechanical Braking System (MBS) has to fulfil three main objectives: Reliability - the system must achieve the required level of braking torque, to stop the generator within the specified time. Self-contained being part of the generator safety system, critical components must not be shared with similar components of the generator, such as control, auxiliary supply or cooling. Self-monitored - supervising its healthy status, to prevent start-up or initiate a shutdown if the system is not ready.

\section{Mechanical Braking Concept}

\subsection{Overview}

The shaft line of the MBS consists of a flexible coupling type Centa to connect the MBS to the free end of the flywheel, while decoupling the flywheel-generator shaft radial/axial movements and providing electrical isolation to prevent shaft current. Subsequently, a hydraulic dynamometer and a disc brake to dissipate the kinetic energy of rotation and thus to slow down the generator. And last a clutch to engage the disc brake at low speed (Fig. 3).

Table 1: Mechanical Braking System Main Data

\begin{tabular}{ll}
\hline Hydraulic Dynamometer & \\
\hline Type & Piper PH9000 \\
Power capability & $6700 \mathrm{~kW}$ \\
Torque capability & $50 \mathrm{kNm}$ \\
Speed range & $1650-200 \mathrm{rpm}$ \\
Water flow - freewheeling & $1801 / \mathrm{min}$ \\
Water flow - braking & $3800 \mathrm{l} / \mathrm{min}$ \\
Braking time & $6: 30 \mathrm{~min}$ \\
\hline Clutch & \\
\hline Type & Wichita \\
Torque capability & $45 \mathrm{kNm}$ \\
Speed range & $1650-0 \mathrm{rpm}$ \\
Pneumatic pressure & $8.5 \mathrm{bar}$ \\
Change over time & $0: 40 \mathrm{~min}$ \\
\hline Disc Brake & \\
\hline Type & Wichita \\
Torque capability & $20 \mathrm{kNm}$ \\
Speed range & $200-0 \mathrm{rpm}$ \\
Water flow - braking & $1000 \mathrm{l} / \mathrm{min}$ \\
Pneumatic pressure & $1.8 \mathrm{bar}$ \\
Braking time & $1: 40 \mathrm{~min}$ \\
\hline Total braking time & \\
\hline $1650-0$ rpm & $8: 50 \mathrm{~min}$ \\
\hline
\end{tabular}

The assembly is mounted on a steel supporting structure attached to the floating concrete baseplate of EZ4 (Fig. 4).

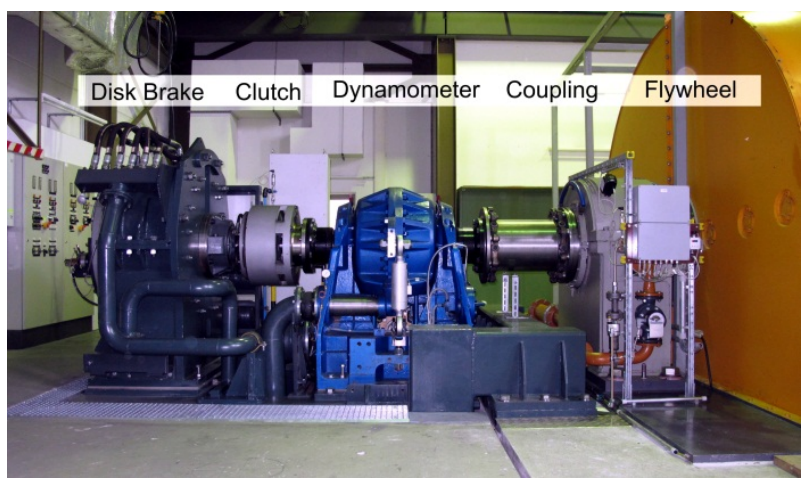

Fig. 3. Mechanical Braking System Shaft Line

\subsection{Design Studies and Simulations}

Extensive computer simulations and a hardware mock-up were undertaken at the design stage of this oneoff project.

Company IDAC Integrated Design \& Analysis Consultant prepared a finite elements model of the system (Fig. 4). On the basis of this model, stress analyses of the steel supporting structure were performed. It is stringent that there are no mechanical resonances in the range of $0-30 \mathrm{~Hz}$, which represents the range of the mechanical operating frequency of the flywheel-generator $(0-27.5 \mathrm{~Hz})$. The outcome was a 14 tonnes supporting structure, made of $16 \mathrm{~mm}$ thick box sections, to carry the 11 tonnes of the MBS.

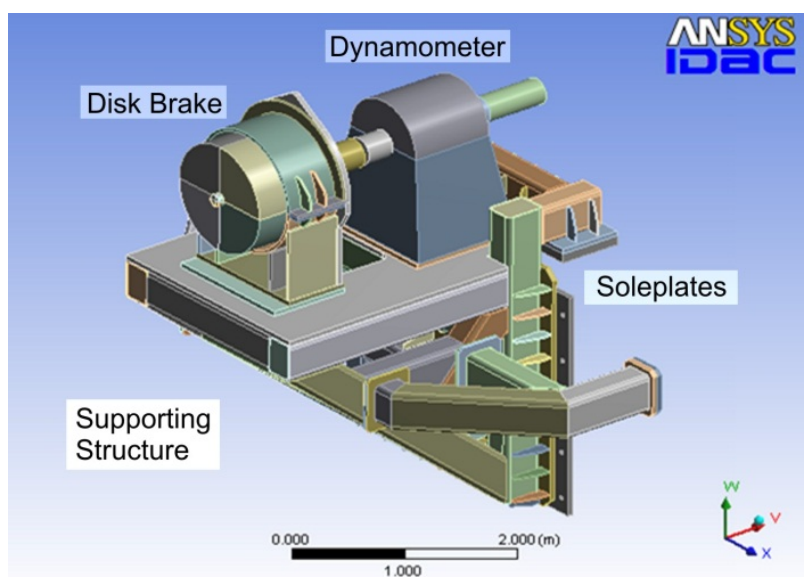

Fig. 4. 3D Model of the MBS and Baseplate Extension

Further on, a 1:10 mock-up of the cooling water tank was built by IPP to verify the hot/cold water mix in the multi-chamber design of the water tank. To avoid water cavitation and erosion of the rotor discs, a maximum temperature of $60^{\circ} \mathrm{C}$ is specified for the circulating water at the outlet of the dynamometer. With a maximum water temperature rise of $25 \mathrm{~K}$ within the dynamometer, the inlet temperature has to be limited to $\sim 30^{\circ} \mathrm{C}$. In view of the limited space and the large water volume required $\left(\sim 20 \mathrm{~m}^{3}\right)$, separate hot/cold water tanks were excluded. A single multi-chambers water tank with recirculation was adopted (Fig. 7). On one hand, this prevents the hot water from the dynamometer outlet to mix with the cold tank water at the inlet to the dynamometer. On the other 
hand, it maintains a high water temperature difference within the tank to ensure the optimum cooling rate of the water after the completion of the braking and therefore to minimise the downtime before restart $(\sim 30 \mathrm{~min})$. Computer simulations, aided with a 1:10 hardware mock-up, showed that a 5-chamber tank with a volume of $15 \mathrm{~m}^{3}$ was the optimum. Full braking tests during commissioning proved that the maximum water temperature stays below $60^{\circ} \mathrm{C}$ at the outlet of the dynamometer. The maximum water temperature in the tank is $45^{\circ} \mathrm{C}$. Re-cooling takes between 30 and $35 \mathrm{~min}$.

\subsection{Supporting Structure and Shaft Alignment}

To maintain the relative static/dynamic movements of the flywheel-generator shaft and the MBS shaft within the limits of the flexible coupling, the MBS must be mounted on the same floating concrete structure of the flywheel-generator. Therefore the baseplate was extended by means of a steel structure built by company Whittaker Engineering. To guarantee a high stiffness of the completed structure as well as an accurate reference surface for the fixation of the steel structure, a vertical $2.4 \mathrm{~m} \times 3.0 \mathrm{~m} 50 \mathrm{~mm}$ thick soleplate and a horizontal $0.6 \mathrm{~m} \times 2.6 \mathrm{~m} 50 \mathrm{~mm}$ thick soleplate were fitted to the concrete bloc with (19-off $50 \mathrm{~mm}$ diameter) studs and (7-off M36) resin anchor bolts, the interspace being filled with epoxy grout before tightening the studs/bolts.

To ensure an accurate alignment of the MBS with the generator shaft line, the positioning of the two soleplates was controlled with the aid of a 3D laser tracker provided by company Faro Technologies.

By the 25 tonnes weight of the supporting structure and the MBS applied at one side of the generator, the generator baseplate sank by $3 \mathrm{~mm}$ at this side. To bring the baseplate back to a horizontal position, the springs and dampers had to be adjusted. This was done by the manufacturer of the damping system company Gerb Schwingungsisolierungen.

\subsection{Hydraulic Dynamometer}

The principle of the hydraulic dynamometer is shown in Fig. 5. A rotor disc is located between two stator discs. On either face of the rotor disc there is an annular recess, which is subdivided into cups by radial vanes inclined at $45^{\circ}$. The stator discs have cups that match those of the rotor disc. Water is fed under pressure in the stator cups through the vanes and exhausts the stator cups at the back. The rotation of the rotor disc induces a toroidal vortex in the cups. The velocity of circulating water in the cups and the depth of water in the cups determine the resistive torque applied to the rotor disc. The stator discs are located in a casing fitted either side with trunnion bearings, so that the stator casing is free to rotate. The rotation of the stator casing is restrained by a torque arm connected to a strain gauge. This measures the torque applied by the dynamometer to the prime mover, here the flywheel-generator. A butterfly valve at the outlet regulates the amount of water in the dynamometer.

In this application, the dynamometer has two operating modes, namely: "Braking" and
"Freewheeling" (Fig. 7). In the "Braking" mode, the rated water flow $(3800 \mathrm{l} / \mathrm{min})$ is fed by the pump P1 and the torque is controlled by the butterfly valve. In the "Freewheeling" mode, a minimum of water (180 1/min) is fed by pump P2 in the dynamometer to take away friction losses due to air circulation in the cups, while the butterfly valve is fully open. This ensures a minimum loss power of the dynamometer (measured: $\sim 60 \mathrm{~kW}$, guaranteed: $\leq 250 \mathrm{~kW}$ ).

With the dynamometer, a braking time from the maximum speed of $1650 \mathrm{rpm}$ down to $200 \mathrm{rpm}$ of approximately 6.5 min can be achieved (Table 1).

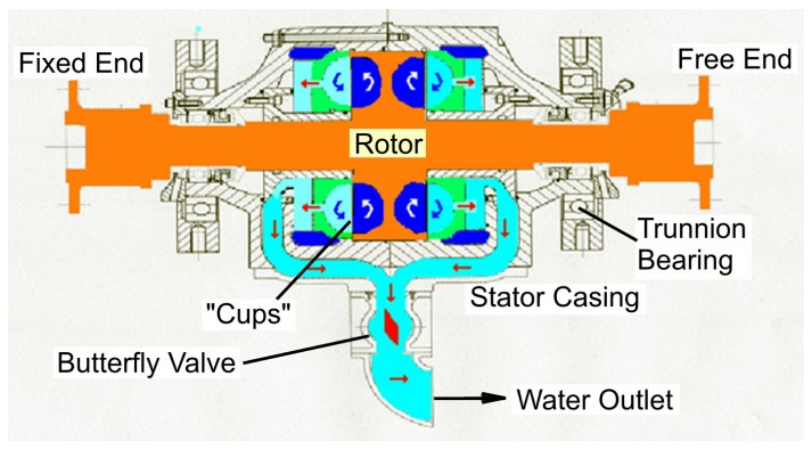

Fig. 5. Dynamometer Principle

\subsection{Clutch and Disk Brake}

At very low speed the dynamometer is not efficient any more. A pneumatically actuated, spring released and water cooled disc brake provides the remaining braking power (Fig. 6). For the disc brake, a maximum speed of $650 \mathrm{rpm}$ is allowed. Therefore a clutch disconnects the disc brake from the shaft line during normal operation. Both, clutch and disc brake were built by Wichita Company. Although designed to engage at $400 \mathrm{rpm}$, the clutch is engaged at $200 \mathrm{rpm}$, given the better than expected torque of the dynamometer at low speed. This reduces the wear of the brake pads. The disc brake brings the generator to standstill within around $2.5 \mathrm{~min}$.

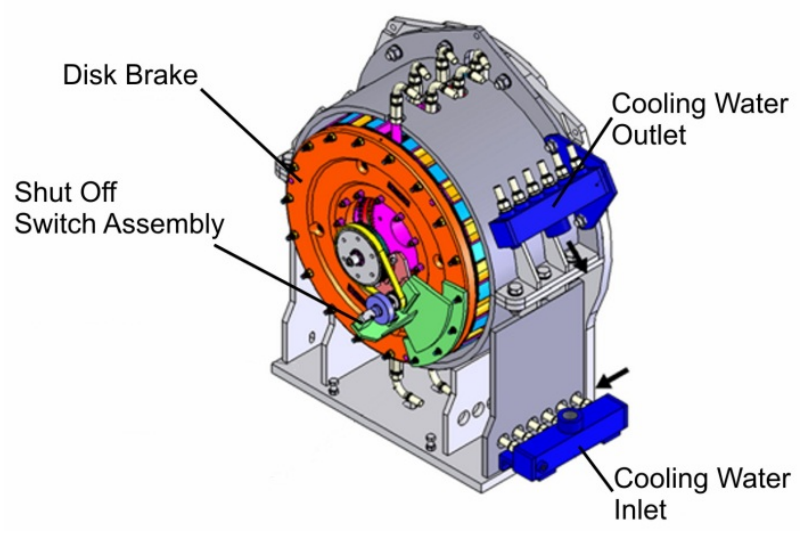

Fig. 6. Disk Brake Assembly

\subsection{Water Cooling Unit}

The water cooling unit (WCU) has to fulfil two main tasks (Fig. 7): While the generator is running in normal operation, pump P2 supplies a reduced water flow for the cooling of the dynamometer. As soon as an emergency stop is requested, pump P1 provides the full water flow to the dynamometer to brake the system down. At 
$200 \mathrm{rpm}$ (changeover from dynamometer to disc brake) pump P1 stops and P3 delivers cooling for the disc brake $(1000 \mathrm{l} / \mathrm{min})$. The water in the tank is re-cooled from the IPP well water circuit by pump P4 $(820 \mathrm{l} / \mathrm{min})$ via a heat exchanger. The tank and pipework were installed by company Reichhardt Industriemontagen. The well water flow freewheeling (light load) is $570 \mathrm{l} / \mathrm{min}$. While braking (full load) and during the re-cooling period, it is increased to $1200 \mathrm{l} / \mathrm{min}$.

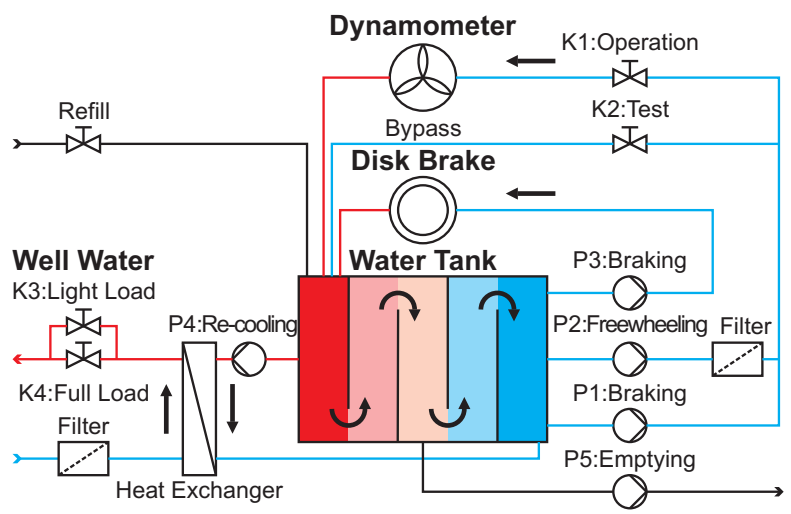

Fig. 7. Water Cooling System

\subsection{Control and Protection}

At the MBS, three control systems can be distinguished and work very close together to keep the generator in a safe state and to slow it down in case of emergency (Fig. 8). In the centre there is the generator's Simatic control. This PLC controls the operation of the generator and monitors its status. If a major fault occurs (safety level SE9 or SE10), it initiates - depending on the reason of fault - the electrical Generator Braking System (GBS) and/or the Mechanical Braking System. Even if a sub-system of the MBS should fail, it is still possible to brake with the remaining facilities. The overall control of the MBS and the integration into the existing generator control were implemented by company Siemens Industrial Automation Systems.

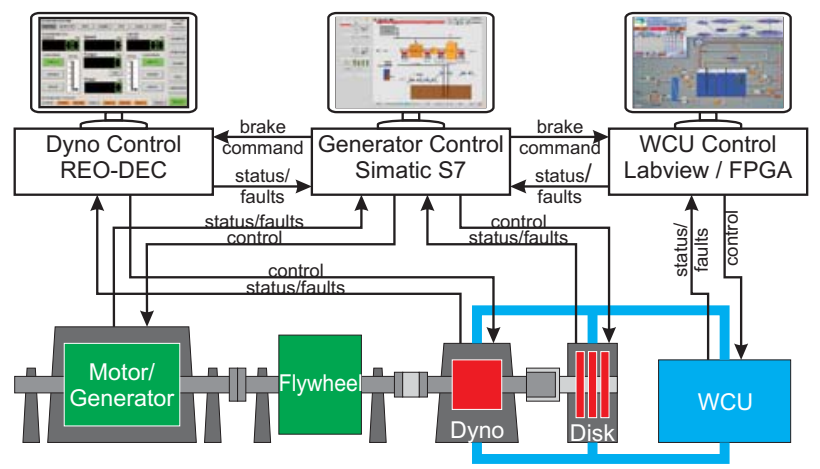

Fig. 8. Control and Interlock System

The REO-DEC controller is an integrated part of the dynamometer (dyno) and actively controls the torque of the dynamometer while braking. Further on it supervises the dynamometer status (e.g. bearing lubrication interval) and reports it back to the generator control.

For the control of the WCU, a 4 core PXI computer type 8231 with hypervisor system is used [1]. The hypervisor system allows the use of the same controller for real time (data exchange) as well as for Windows (visualisation) applications. The complete control is implemented in FGPA type PXI 7854 LX110 with I/O extensions (C-Modules). The program is based on a state machine. Depending on the commands received from the generator control, the WCU control operates the pumps and valves of the WCU. Further on it supervises the status of the WCU (e.g. states, temperatures, flow rates, pressure, ...), notifies the generator control accordingly and visualises it on a touchscreen monitor.

\section{Commissioning}

A special test mode at the WCU control allows the operation and testing of every single state, pump and valve during standstill of the generator and with the water bypass activated.

The successful commissioning of the dynamometer took place in December 2010. Intensive tests were performed to check all imaginable fault scenarios. The complete system, including clutch and disc brake, is in operation since spring 2011. The total braking time of the MBS alone is below $9 \mathrm{~min}$ and thus well below the allowed time window of $10 \mathrm{~min}$. The MBS together with the electrical (generator) braking results in a braking time below $3 \mathrm{~min}$.

\section{Operational Experience and Improvements}

Since the commissioning the system operates without major problems. A few faulty activations from the REO control at the beginning could quickly be solved. A faulty pump had to be repaired by the supplier.

To enhance the reliability of this safety system, a weekly automated test cycle was implemented at the WCU control. Every valve and pump is tested and only if the test is successful the start-up of the generator is enabled.

\section{Conclusion}

The hydraulic dynamometer, typically used in test stand for large diesel motors, offers a compact and an innovative solution for the dumping of large kinetic energy stored in flywheel-generators. Its main advantage lies in that the converted thermal energy is deposited in a circulating fluid (water) rather than in copper or steel (i.e. electromagnetic brake or mechanical disc brake), thereby reducing the size and mass of the energy converter coupled to the flywheel-generator. It is however important that the design of the active parts (stator/rotor) ensures a flat torque/power characteristics in a wide speed range. This application shows that the standard hydraulic dynamometer is also suitable for spending a great part of its operating life in "Freewheeling" mode, rather than in the "Braking" mode.

\section{References}

[1] A. Sigalov, C.-P. Käsemann, I. Goldstein, Steuerung der Wasserkühlanlage der mechanischen Bremse eines 220MVA-Schwungrad-Generators, Virtuelle Instrumente in der Praxis (2011) 410-413 